\title{
Knowledge and Level of Adherence to COVID-19 Preventive Measures: A Bi-national Web-based Survey in Africa
}

Olabode E Omotoso ( $\square$ olabodeomotoso@gmail.com )

University of Ibadan https://orcid.org/0000-0002-9291-9289

Precious-Paul Awoyemi

University of Ibadan

Victor James Wahab

Federal University of Technology, Akure

Mahmoud Ragab

Benha University, Egypt

John O. Teibo

University of São Paulo, Brazil

Opeyemi Akinfe

University of Ibadan

Amira Matareek

Mansoura University, Egypt

\section{Research Article}

Keywords: COVID-19, adherence, knowledge, preventive measures, Africa

Posted Date: December 28th, 2020

DOI: https://doi.org/10.21203/rs.3.rs-136838/v1

License: (9) (1) This work is licensed under a Creative Commons Attribution 4.0 International License. Read Full License

Version of Record: A version of this preprint was published at Saudi Journal for Health Sciences on August 16th, 2021. See the published version at https://doi.org/10.4103/sjhs.sjhs_272_20. 


\section{Abstract}

With increasing daily incidence and mortality, the novel coronavirus disease (COVID-19) has been a threat to public health and human co-existence since its outbreak in December 2019. Globally, COVID-19 has ravaged over 200 countries and has resulted in over a million deaths within few months of its outbreak. As the disease curve begins to flatten in most countries, the instituted regulatory guidelines were receded to mitigate the effect on citizens and national economy. Hence, we assessed the knowledge and level of adherence of Nigerians and Egyptians to the COVID-19 precautionary measures. A web-based crosssectional questionnaire was utilized to obtain 915 respondents via a convenient sampling technique. Most Egyptians (87\%) had satisfactory COVID-19 knowledge compared to Nigerians (40\%). Age (18- 30 years), tertiary education and educational background (medical or scientific) were major factors that influenced respondents' COVID-19 knowledge levels. The level of adherence of most respondents (59.1\%) to COVID-19 precautionary measures was unsatisfactory. Although majority $(73 \%)$ believes that the precautionary measures are required to curtail the menace of COVID-19. Only a few (57\%) use face mask in public, avoided touching their eyes or mouth with unwashed hands (45\%), avoided non-essential travel (36\%), go out only for essential reasons (28\%) and keep at least 2-meters distance (27\%). The coronavirus pandemic and the instituted regulatory policies had a negative effect on respondents' education, school or job $(90.3 \%)$, finance $(87.9 \%)$ and social interaction (87.5\%).

Assessing the knowledge and level of adherence to COVID-19 precautionary measures can prove effective in identifying and modifying measures in place to reduce the COVID-19 burden. Information on social media platforms on COVID-19 must be monitored and verified to ensure the right information is disseminated. Both countries showed a good knowledge of the disease but adherence to the precautionary measures is unsatisfactory. We therefore encourage increased adherence to the guidelines in order to avoid an unnecessary second wave of the disease in Africa. Similarly, with the adverse effect of the pandemic on people's finance, education, job and social interaction, support should be made available to cushion these effects on the populace.

\section{Introduction}

The novel coronavirus disease (COVID-19), caused by the severe acute respiratory syndrome coronavirus 2 (SARS-CoV-2) has been a threat to public health and human co-existence since its outbreak in December 2019. Within few months of its outbreak, COVID-19 has ravaged over 200 countries and has resulted in over a million deaths globally with increasing daily burden (1). Globally, as of 15:06 GMT, 01 December 2020, there have been 63,756,626 confirmed cases of COVID-19 infection, including 1,477,422 reported deaths (2). Africa accounts for 2,188,092 (3.43\%) of the confirmed cases and 52,096 (3.53\%) reported deaths due to COVID-19 infection globally (2).

Coronaviruses are single-stranded RNA viruses and are causative pathogen of highly pathogenic respiratory infections like the severe acute respiratory syndrome (SARS), Middle East respiratory syndrome (MERS) and the novel COVID-19 (3). The novel SARS-CoV-2 is highly pathogenic and 
contagious. According to World Health Organization (WHO), most infected persons will experience mild to moderate respiratory illness. More so, most patients will recover without requiring special intervention (4). People with co-morbidities (diabetes, HIV/AIDS, cancer, cardiovascular disease, other respiratory infections and immune-compromising ailments) and older people are more prone to develop more severe symptoms and disease outcome (1). Common symptoms of coronavirus infection include but are not limited to; fever, dry cough, difficulty in breathing or shortness of breath, loss of speech or locomotion, sore throat, diarrhoea and fatigue or body weakness (1).

During the first few months of the outbreak of COVID-19, it was predicted that the virus would have a debilitating effect in Africa due to the poor health infrastructure in place and a large number of immunecompromised population. Surprisingly, high-income countries have been the worst hit by the pandemic, despite the advanced healthcare system in place (5). During the peak of the disease transmission, most countries enforced regulatory policies, preventive measures, and social and public health guidelines in line with WHO recommendation to curtail the spread of the disease (6). However, these regulations, most especially lockdown and ban on public gatherings had a negative toll on citizens in most low- and midincome countries that could not provide palliatives and/or reliefs for their citizens. As the disease curve begins to flatten in most countries, most of the regulatory guidelines were subsided to mitigate the effect on citizens, national economy and social interaction.

Adherence to preventive and public health guidelines (the use of alcohol-based hand sanitizers, washing of hands, respiratory etiquettes and other regulatory policies) is important in protecting oneself and inhibiting the spread of COVID-19 (1). With increasing daily human transmission across the world, knowledge about the disease, how it spreads and adherence to preventive measures is essential. This present study aims to assess public knowledge and level of adherence to the instituted guidelines against COVID-19 infection. The information acquired will assist in understanding predictive factors that influence Nigerians and Egyptians knowledge about the pandemic and that which promotes adherence to preventive measures. These findings would also provide valuable information for national and community policy makers in understanding the citizens' perception of the established regulatory policies. This will contribute immensely to the ongoing fight against COVID-19.

\section{Materials And Methods}

\section{Study design}

The research instrument administered was designed as a cross-sectional questionnaire in Arabic and English, the official language of Egypt and Nigeria respectively. The questionnaire was released online on October 18, 2020, after the total lockdown has been rescinded in both countries and collated on November 20, 2020. The choice of both African countries - Nigeria and Egypt was facilitated by virtue of them having the highest burden of COVID-19 in West- and North-Africa respectively. The COVID-19 index cases in Africa were also first reported in Egypt and Nigeria. 
The inclusion criteria were individuals living in Egypt and Nigeria who gave consent for participation and are above 18 years of age. Non-consenting individuals and those below 18 years of age were excluded from the study. For sample size calculation, we anticipated that $50 \%$ of the study participants would have a satisfactory knowledge level of the dependent variables (knowledge of COVID-19 and adherence to the public health guidelines) at a $99 \%$ confidence level. Using the Open Source Epidemiologic Statistics for Public health web interface (7), v.3.01, the required sample size was 664 . We added a $35 \%$ contingency to make the required minimum sample size 897 respondents from both countries. In order to adhere to the social distancing guidelines, a paper-based questionnaire format was not feasible for the present study; we therefore opted for a web-based questionnaire. Due to the differing internet penetration rate (8) in Nigeria (61.2\%) and Egypt (48.1\%), the respondents were sampled in a ratio of (Nigeria) 2:1 (Egypt) using a convenience sampling method to reach the participants via social media platforms (WhatsApp and Facebook). Respondents were recruited from major cities, Oyo and Lagos state (Nigeria) and from Egypt; Cairo and Qalyubia Governorate.

\section{Ethical considerations}

This study strictly adhered to the World Medical Association Declaration of Helsinki Ethical principles. Although a low-risk study, no vulnerable (below 18 years) or non-consenting individual was recruited. A short introduction clearly stating the purpose of the study, the average time to complete the questionnaire and voluntary participation was provided to respondents before proceeding to fill the questionnaire. Informed consent was sought and the email of the principal investigator was supplied for any clarification or withdrawal of data from the study.

\section{Questionnaire design}

The administered questionnaires (Arabic and English) were designed using Google forms (Alphabet Inc., California, USA) and pre-validated by two independent reviewers from each country. The questionnaire in Arabic was initially translated to English to ensure items in the questionnaires are communicating the same thing both in English and Arabic and then back-translated. The approved questionnaire can be assessed online (Arabic - https://forms.gle/YNcosp8pYbBYKgzx7 and English - https://bit.ly/2HzpSCR). The questionnaires were pre-tested on 20 respondents which were not included in the analysis. The instrument (designed as a questionnaire) consists of 5 major parts:
a. Socio-demographic information of respondents
b. Respondents' knowledge of the novel coronavirus infection

c. Level of adherence to COVID-19 preventive measures or social and public health guidelines

d. Role of media, government and social groups (religious bodies, medical association, peers and social societies) in creating awareness and ensuring adherence to the guidelines 
e. Effect of the pandemic and instituted policies (lockdown and social distancing) on respondent's finance, school, education or job and social interaction.

\section{Data analysis}

Responses were imported from Google form as Microsoft Excel spreadsheet. Collated data from Egypt in Arabic was translated to English. All data were then analyzed using the Statistical Package for the Social Sciences (SPSS) software, v.20. Descriptive statistics were used to summarize respondents' sociodemographic information. Knowledge and adherence were assessed using a numbered scoring pattern. The dependent variables were computed and then binned into an equal percentile (50\%) based on mean scores to categorize the knowledge and adherence level. Respondents with numeric scores greater than the mean scores were classified as satisfactory (satisfactory knowledge or adherence level) and viceversa. The association between the demographics (independent variables) and the dependent variables were tested using Cross-tabs. Preliminary analyses were performed to ensure no violation of the assumptions of normality, linearity and homoscedasticity. Where required correlation analysis was performed to test for relationships between variables. Chi-Square test and One-way analysis of variance (ANOVA) were used to test for differences in the knowledge and adherence score across the independent variables. Statistically significant results $(P<0.05)$ were subjected to further significant test.

\section{Results}

\section{Respondents' demographics}

A total of 915 respondents (Nigeria - 610 and Egypt - 305) were included in this study. Most respondents were female $(62.1 \%, n=568 / 915)$, resides in urban area $(65.14 \%, n=596 / 915)$, never married/single $(82.73 \%, n=757 / 915)$ and between the ages of $21-30$ years of age $(65.25 \%, n=$ $597 / 915)$. Similarly, majority of the respondents have at least a University degree $(83.28 \%, n=762 / 915)$ and have a scientific background $(48.2 \%, \mathrm{n}=441 / 915)$ (Table 1).

Table 1. Demographics of respondents in the present study $(n=915)$. 


\begin{tabular}{|c|c|c|c|c|}
\hline \multicolumn{2}{|l|}{ Variables } & \multicolumn{2}{|c|}{ Number of respondents (\%) } & \multirow{2}{*}{$\begin{array}{l}\text { Total } \\
915\end{array}$} \\
\hline Country & & $\begin{array}{l}\text { Nigeria }(\mathrm{n}= \\
610)\end{array}$ & $\begin{array}{l}\text { Egypt } \quad(\mathrm{n}= \\
305)\end{array}$ & \\
\hline \multirow[t]{2}{*}{ Gender } & Female & $327(58 \%)$ & $241(42 \%)$ & 568 \\
\hline & Male & $283(82 \%)$ & $64(18 \%)$ & 347 \\
\hline \multirow[t]{2}{*}{ Marital status } & Never married/single & $478(63 \%)$ & $279(37 \%)$ & 757 \\
\hline & Ever married & $132(84 \%)$ & $26(16 \%)$ & 158 \\
\hline \multirow{4}{*}{$\begin{array}{ll}\text { Age } & \text { range } \\
\text { (years) } & \\
\end{array}$} & $18-20$ & $55(32 \%)$ & $117(68 \%)$ & 172 \\
\hline & $21-30$ & $427(72 \%)$ & $170(28 \%)$ & 597 \\
\hline & $31-40$ & $94(88 \%)$ & $13(12 \%)$ & 107 \\
\hline & $>41$ & $34(87 \%)$ & $5(13 \%)$ & 39 \\
\hline \multirow[t]{3}{*}{ Education } & Up to college & $74(48 \%)$ & $79(52 \%)$ & 153 \\
\hline & Bachelors & $325(62 \%)$ & $199(38 \%)$ & 524 \\
\hline & Postgraduate & $211(89 \%)$ & $27(11 \%)$ & 238 \\
\hline \multirow{3}{*}{$\begin{array}{ll}\text { Area } & \text { of } \\
\text { residence }\end{array}$} & Urban & $408(68 \%)$ & $188(32 \%)$ & 596 \\
\hline & Sub-urban & $172(74 \%)$ & $62(26 \%)$ & 234 \\
\hline & Rural & $30(35 \%)$ & $55(65 \%)$ & 85 \\
\hline \multirow[t]{3}{*}{ Background } & Medical & $100(52 \%)$ & $92(48 \%)$ & 192 \\
\hline & Scientific & $252(57 \%)$ & $189(43 \%)$ & 441 \\
\hline & $\begin{array}{l}\text { Non-Scientific or non- } \\
\text { medical }\end{array}$ & $258(91 \%)$ & $24(9 \%)$ & 282 \\
\hline
\end{tabular}

\section{Sociodemographic data in relation to respondents' COVID-19 knowledge and adherence to public health guidelines}

Satisfactory COVID-19 knowledge was observed in most Egyptians $(265,87 \%)$ compared to Nigerians $(246,40 \%)$. Females $(349,61 \%)$ had satisfactory COVID-19 knowledge compared to male $(162,47 \%)$. Respondents within the age group 18 - 30 years had a better COVID-19 knowledge compared to other age groups. Respondents who had tertiary education (Bachelors - $59 \%$ and postgraduate $-53 \%$ ) had more satisfactory knowledge than those with lower educational level. Respondents with medical background (124, $65 \%$ ) had more satisfactory knowledge of COVID-19 compared to those with scientific $(277,63 \%)$ and others with non-medical or non-scientific background (110, $39 \%)$. Despite the satisfactory COVID-19 knowledge of respondents, the respondents' level of adherence to the COVID-19 social and public health guidelines was poor as only (132, $43 \%)$ Egyptians and $(242,40 \%)$ Nigerians had satisfactory scores. This was a similar trend across all socio-demographics (Table 2 ). 
Table 2. Relationship between sociodemographic data and outcome variables 


\begin{tabular}{|c|c|c|c|}
\hline Variables & & Satisfactory (\%) & Unsatisfactory (\%) \\
\hline \multicolumn{3}{|c|}{ Knowledge of COVID-19 } & \\
\hline \multirow[t]{2}{*}{ Country } & Nigeria & $246(40 \%)$ & $364(60 \%)$ \\
\hline & Egypt & $265(87 \%)$ & $40(13 \%)$ \\
\hline \multirow[t]{2}{*}{ Gender } & Female & $349(61 \%)$ & $219(39 \%)$ \\
\hline & Male & $162(47 \%)$ & 185 (53 \%) \\
\hline \multirow[t]{2}{*}{ Marital status } & Never married/single & $442(58 \%)$ & $315(42 \%)$ \\
\hline & Ever married & $69(44 \%)$ & $89(56 \%)$ \\
\hline \multirow[t]{4}{*}{ Age range (years) } & $18-20$ & $113(66 \%)$ & $59(34 \%)$ \\
\hline & $21-30$ & $329(55 \%)$ & $268(45 \%)$ \\
\hline & $31-40$ & $53(50 \%)$ & $54(50 \%)$ \\
\hline & $>41$ & $16(41 \%)$ & $23(59 \%)$ \\
\hline \multirow[t]{3}{*}{ Education } & Up to college & $74(48 \%)$ & $79(52 \%)$ \\
\hline & Bachelors & $311(59 \%)$ & $213(41 \%)$ \\
\hline & Postgraduate & $126(53 \%)$ & $112(47 \%)$ \\
\hline \multirow[t]{3}{*}{ Residence } & Urban & $324(54 \%)$ & $272(46 \%)$ \\
\hline & Sub-urban & $127(54 \%)$ & $107(46 \%)$ \\
\hline & Rural & $60(71 \%)$ & $25(29 \%)$ \\
\hline \multirow[t]{3}{*}{ Background } & Medical & $124(65 \%)$ & $68(35 \%)$ \\
\hline & Scientific & $277(63 \%)$ & $164(37 \%)$ \\
\hline & Non-Scientific or non-medical & $110(39 \%)$ & $172(61 \%)$ \\
\hline \multicolumn{4}{|c|}{ Adherence to social and public health guidelines } \\
\hline \multirow[t]{2}{*}{ Country } & Nigeria & $242(40 \%)$ & $368(60 \%)$ \\
\hline & Egypt & $132(43 \%)$ & $173(57 \%)$ \\
\hline \multirow[t]{2}{*}{ Gender } & Female & $237(42 \%)$ & $331(58 \%)$ \\
\hline & Male & $137(39 \%)$ & $210(61 \%)$ \\
\hline \multirow[t]{2}{*}{ Marital status } & Never married/single & $320(42 \%)$ & $437(58 \%)$ \\
\hline & Ever married & $54(34 \%)$ & $104(66 \%)$ \\
\hline
\end{tabular}




\begin{tabular}{|l|l|l|l|}
\multirow{4}{*}{ Age range (years) } & $18-20$ & $71(41 \%)$ & $101(59 \%)$ \\
\cline { 2 - 4 } & $21-30$ & $249(42 \%)$ & $348(58 \%)$ \\
\cline { 2 - 4 } & $31-40$ & $48(45 \%)$ & $59(55 \%)$ \\
\cline { 2 - 4 } & $>41$ & $6(15 \%)$ & $33(85 \%)$ \\
\hline \multirow{5}{*}{ Education } & Up to college & $58(38 \%)$ & $95(62 \%)$ \\
\cline { 2 - 4 } & Bachelors & $226(43 \%)$ & $298(57 \%)$ \\
\cline { 2 - 4 } & Postgraduate & $90(38 \%)$ & $148(62 \%)$ \\
\hline \multirow{5}{*}{ Background } & Urban & $244(41 \%)$ & $352(59 \%)$ \\
\cline { 2 - 4 } & Sub-urban & $89(38 \%)$ & $145(62 \%)$ \\
\cline { 2 - 4 } & Rural & $41(48 \%)$ & $44(52 \%)$ \\
\cline { 2 - 4 } & Sedical & $88(46 \%)$ & $104(54 \%)$ \\
\cline { 2 - 4 } & Scientific & $183(41 \%)$ & $258(59 \%)$ \\
\hline
\end{tabular}

\section{Knowledge of COVID-19 and adherence to preventive measures among respondents}

From a maximum obtainable score of 5 , most respondents $(n=511 / 915,55.9 \%)$ had satisfactory knowledge of COVID-19. Although majority of the respondents $(n=825 / 915,90.2 \%)$ believe the coronavirus is real as a global pandemic, many Nigerians $(n=298 / 610,48.9 \%)$ and very few Egyptians $(n=44 / 305,14.4 \%)$ think that the coronavirus is a hoax. This might probably be attributed to only very few respondents ( $n=321 / 915,35.1 \%$ ) who knew anyone who has ever been infected with the virus. Most of the respondents $(n=805 / 915,88 \%$ ) identified that there is no approved drug or vaccine as of now to prevent the novel COVID-19.

From a maximum obtainable score of 11 , most respondents $(n=541 / 915,59.1 \%)$ had unsatisfactory level of adherence to COVID-19 preventive measures. Even though majority of respondents (73\%) believe that the preventive measures are required to curtail the menace of COVID-19. Although, most respondents (64.4\%) wash their hands with soap and water frequently, only few avoided touching their eyes or mouth with unwashed hands (45.1\%), avoided non-essential travel (36.4\%), go out only for essential reasons (28.2\%), and keep at least 2-meters distance (27.1\%). Likewise, although most respondents (81.6\%) identified that the use of face mask is effective as a preventive measure, only few (57.2\%) use face mask in public. 
Most respondents (51 \%) do not know the coronavirus symptoms. Meanwhile, $(n=491 / 805,53.7 \%)$ identified to have experienced COVID-19 symptom(s) since the outbreak. From those $(n=437)$ who responded to action taken after COVID-19 symptoms manifestation, majority did nothing (50.34\%), some took drugs or herbs $(25.17 \%)$ and others self-isolated or quarantined $(6.86 \%)$.

Only few $(47.3 \%)$ of the respondents are confident that the media are presenting proper news on the COVID-19 preventive measures. A good number of the respondents believe the role of the following; medical associations $(93.3 \%)$, media $(86.4 \%)$, religious bodies (83.1\%), peers $(77.2 \%)$, government $(76.2$ $\%)$ and social society groups (71.5\%) are helpful in their contribution to promoting knowledge and adherence to COVID-19 preventive measures. Meanwhile only 485 (53\%) respondents rate government's effort in combatting the pandemic as satisfactory. The coronavirus pandemic had negative effect on respondents' education, school or job (826, $90.3 \%)$, finance $(804,87.9 \%)$ and social interaction $(801,87.5$ $\%)$. Very few respondents $(341,37.3 \%$ ) are likely to communicate with others on the need for adherence to the COVID-19 preventive measures (Supplementary S1). Respondents' education, school or job (95\%), followed by social interaction ( $87 \%$ ) and finances ( $85 \%$ ) was the most affected by the COVID-19 pandemic for most Egyptians. Most Nigerians reported a severe effect of the pandemic on their finances (89\%), followed by education, school or job (88 \%) and social interaction (88\%).

\section{Influence of Predictors on COVID-19 Knowledge and Adherence to Public Health Measures}

Using Chi-square test, the difference in the knowledge of male (61\%) and female respondents (47\%) about COVID-19 (as shown in Table 2) was statistically significant $(P<0.05)$. Meanwhile, there was no significant difference $(P=0.329)$ in the level of adherence of males $(42 \%)$ and females $(39 \%)$ as shown in Table 2 to COVID-19 preventive measures. The difference in the knowledge of respondents who are never married or single (58 \%) and married (44\%) about COVID-19 was statistically significant (P = 0.034). Meanwhile, there was no significant difference $(P=0.217)$ in the level of adherence of respondents across marital status to COVID-19 preventive measures. There was also no significant difference $(P=0.076)$ across educational status in both respondents' knowledge and level of adherence to COVID-19 preventive measures.

The impact of educational background on knowledge of COVID-19 was explored using One-way betweengroups ANOVA. Levene's test significance value of 0.086 depicts non-violation of the homogeneity of variance assumption. There was a statistically significant difference at the $\mathrm{P}<0.01$ in COVID-19 knowledge scores for the three educational background groups $[F(2,912)=33.59, P=0.005]$. The Posthoc comparisons using the Tukey HSD test indicated that the mean score for respondents with medical (mean= $3.74 \pm 1.2 \mathrm{SD}$ ) and scientific background (mean= $3.75 \pm 1.05 \mathrm{SD}$ ) was significantly different from those with non-medical or non-scientific background (mean= $3.07 \pm 1.25 \mathrm{SD}$ ); the effect size $(0.069)$, calculated using eta squared depicts a large effect size. As shown in Table 2, respondents with medical or scientific background have satisfactory knowledge of COVID-19 (401/511, 78.47\%) compared to other respondents with non-medical or non-scientific background (110/511, $21.53 \%)$. 
The impact of educational background was likewise explored on level of adherence to COVID-19 preventive measures. Levene's test significance value of 0.538 depicts non-violation of the homogeneity of variance assumption. There was a statistically significant difference at the $P<0.01$ level in adherence level scores for the three educational background groups $[F(2,912)=7.429, P=0.000]$. The Post-hoc comparisons using the Tukey HSD test indicated that the mean score for respondents with medical (mean= $6.26 \pm 2.8 \mathrm{SD}$ ) and scientific background (mean= $5.78 \pm 2.8 \mathrm{SD}$ ) was significantly different from those with non-medical or non-scientific background (mean= $5.25 \pm 2.9 \mathrm{SD}$ ); the effect size (0.02), calculated using eta squared depicts a small effect size.

The impact of age on adherence to COVID-19 preventive measures was explored. Levene's test significance value of 0.12 depicts non-violation of the homogeneity of variance assumption. There was a statistically significant difference at the $\mathrm{P}<0.05$ level in adherence to preventive measures scores for the age groups $[F(3,911)=2.632, P=0.034]$. The Post-hoc comparisons using the Tukey HSD test indicated that the mean score for respondents between 21-30 years (mean= 5.77 $\pm 2.86 \mathrm{SD}$ ) and 31-40 years (mean= $5.88 \pm 3.01 \mathrm{SD}$ ) was significantly different from 18-20 years (mean= $5.71 \pm 2.69 \mathrm{SD}$ ) and $>41$ years (mean $=4.49 \pm 2.55 \mathrm{SD}$ ); the effect size $(0.01)$, calculated using eta squared depicts a small effect size. Meanwhile, there was no significant difference in the COVID-19 knowledge score across all age groups.

The relationship between knowledge of COVID-19 and adherence to preventive measures was investigated using Pearson product-moment correlation coefficient. There was a moderate positive correlation between the two variables $\left[r=0.251^{\star \star}, N=915, P=0.01\right]$, with high knowledge level of COVID-19 associated with a higher level of adherence to preventive measures.

\section{Discussion}

The index case of coronavirus infection in Africa was reported in Egypt and then Nigeria $(9,10)$. As of 23 December 2020, 18:04 GMT, there have been 127,061 and 79,789 confirmed cases of coronavirus infection in Egypt and Nigeria respectively. Likewise, there have been 7,167 and 1,231 reported deaths due to COVID-19 from Egypt and Nigeria respectively (2). Due to the low testing rate in African countries $(2,6)$, it is wide-spread speculation that the COVID-19 burden is under-reported in Africa. To curtail the spread of the coronavirus infection, most nations enforced regulatory policies and preventive measures; restrictions on public gathering and international flight, self-isolation or quarantine, total lockdown or curfew on movement, as well as proper hand-washing and social distancing. Most low- and mid-income countries could not sustain most of these regulatory policies, due to the adverse effect on national economy and lives of its citizens where majority are living below the poverty threshold. Hence, the need to relax some of the restrictions put in place to curtail COVID-19 transmission.

In the light of increasing daily incidence, the present study helps to understand the knowledge and level of adherence of respondents to the COVID-19 preventive measures. Most Egyptians (87 \%) had satisfactory knowledge of COVID-19 compared to Nigerians (40 \%). The poor knowledge of Nigerians might be due to 
the fact that most ( $80 \%$ ) do not know anyone who has ever been infected with the virus, that about half of the respondents ( $49 \%$ ) think that COVID-19 is a hoax in Nigeria and some $(29 \%)$ do not believe the virus is in Nigeria. This supports an earlier study in Nigeria (11) where most of the respondents live in denial of the existence of the disease. In contrast, most Egyptians (66\%) have either been infected or know someone who has been infected with the virus, only a few (14\%) feels COVID-19 is a hoax as well as very few $(6 \%)$ do not believe the virus is in Egypt. Our finding corroborates earlier reports $(3,5)$, where most Egyptians had satisfactory knowledge of the disease. Despite the satisfactory knowledge of the disease, the respondents' adherence to the COVID-19 preventive measures was poor as only (43\%) Egyptians and (40\%) Nigerians had satisfactory level of adherence to the preventive measures. This corroborates other reports in Nigeria (11) and Egypt (5) where the level of adherence was poor. Though not surprising, respondents who had medical background, followed by scientific have more satisfactory knowledge and level of adherence to the COVID-19 preventive measures compared to those with nomedical or scientific background.

While the public health challenges associated with COVID-19 is of importance, the socio-economic challenges it poses must not be ignored. Most Nigerians studied identified a severe effect of the pandemic on their finance (89\%), education, school or job (88\%) and social interaction (88\%). Likewise, most Egyptians identified a severe effect of the pandemic on their education, school or job (95\%), social interaction (87 \%) and finance (85\%). Government and policy makers are encouraged to provide palliatives and appropriate measures to cushion these effects on their citizens. In line with our study, most respondents from a previous study (11) in Nigeria also identified low income as the major effect of COVID-19. While most dental students in Turkey $(74.5 \%)$ identified that the pandemic negatively affected their psychology (12).

Earlier reports $(3,5,12-14)$ have identified social media and internet as major source of information about COVID-19. Most Nigerians (94\%) and Egyptians (71\%) in the present study opine that the media help to gain knowledge and influenced adherence to COVID-19 preventive measures. Surprisingly, only 338 (55\%) Nigerians and 95 (31\%) Egyptians are confident that the media are presenting the proper news on COVID19 preventive measures. Hence, extreme caution must therefore be taking because of unverified information and conspiracy theories about the coronavirus infection propagated on social media channels. Being the major source of information, regulatory bodies should put in more measures to ensure verification of information on social media channels about COVID-19 and other infectious diseases.

In contrast to a high level of adherence in a study on respondents in Arab countries (14), our study showed a very low level of adherence to COVID-19 preventive measures as only $182(30 \%)$ Nigerians and 66 (22\%) Egyptians observe the social distancing of at least 2-meters, $162(27 \%)$ Nigerians and 171 (56 \%) Egyptians avoided non-essential travels, 407 (67\%) Nigerians and 182 (60\%) Egyptians always wash their hands as required and $162(27 \%)$ Nigerians and 96 (31\%) Egyptians only go out for essential reasons. To ensure Africa does not become the next epicenter for coronavirus infection, strict compliance 
to the regulatory policies should be encouraged and proper dissemination of verified information on COVID-19 should be prioritized.

It is disheartening that only 190 (31\%) Nigerians and 151 (50\%) Egyptians are likely to speak to others about best practices on adherence to COVID-19 preventive measures. The major limitation of our study was the low internet coverage in both countries (8). In as much we tried to uphold the preventive measures by employing a web-based survey; those without internet access could not be sampled. Our result also cannot be generalized for both countries as our respondents mostly (65.25\%) are young population (21 - 30 years), those with medical/scientific background $(69.2 \%)$ and those with a University degree $(83 \%)$ who are the major internet users in both countries.

\section{Conclusion}

The COVID-19 outbreak has claimed many lives, stretching global economy, public health and social interaction. Assessing the knowledge and level of adherence to COVID-19 social and public health guidelines can prove effective in identifying and modifying measures in place to reduce the COVID-19 burden. Information on social media platforms on COVID-19 must be monitored and verified to ensure the right information is disseminated. Both countries showed a good knowledge of the disease but adherence to the preventive measures is unsatisfactory. We therefore solicit for increased adherence to the guidelines in order to avoid an unnecessary second wave of the disease. Similarly, with the adverse effect of the pandemic on people's finance, education, job and social interaction, support should be made available to cushion these effects on the populace. Most fear on the low COVID-19 burden in Africa has been hinged on the low testing rate; we therefore encourage a scale-up of both countries testing capacity to ensure the disease burden is not under-reported.

\section{Declarations}

Competing interests: The authors declare no competing interest.

\section{References}

1. Coronavirus [Internet]. [cited 2020 Dec 1]. Available from: https://www.who.int/healthtopics/coronavirus\#tab=tab_1

2. Coronavirus Update (Live): 63,756,626 Cases and 1,477,422 Deaths from COVID-19 Virus Pandemic Worldometer [Internet]. 2020 [cited 2020 Dec 23]. Available from: https://www.worldometers.info/coronavirus/

3. Samir A, Zeinab M, Ibrahim M, Ziady HH, Alorabi M, Ayyad M, et al. Knowledge, Perceptions, and Attitude of Egyptians Towards the Novel Coronavirus Disease (COVID-19). J Community Health [Internet]. 2020;45(5):881-90. Available from: https://doi.org/10.1007/s10900-020-00827-7

4. WHO. Coronavirus disease (COVID-19) pandemic [Internet]. 2020 [cited 2020 Oct 28]. Available from: https://www.who.int/emergencies/diseases/novel-coronavirus-2019 
5. Hager E, Odetokun IA, Bolarinwa O, Ahmed Z, Okechukwu O, Al-Mustapha A. Knowledge, attitude, and perceptions towards the 2019 Coronavirus Pandemic: A bi-national survey in Africa. PLoS One [Internet]. 2020;15(7):1-13. Available from: http://dx.doi.org/10.1371/journal.pone.0236918

6. Omotoso OE. Contributory role of SARS-CoV-2 genomic variations and life expectancy in COVID-19 transmission and low fatality rate in Africa. Egypt J Med Hum Genet. 2020;21(72):1-6.

7. OpenEpi Menu [Internet]. [cited 2020 Nov 17]. Available from: https://www.openepi.com/Menu/OE_Menu.htm

8. Africa Internet Users, 2020 Population and Facebook Statistics [Internet]. [cited 2020 Nov 17]. Available from: https://www.internetworldstats.com/stats1.htm

9. COVID-19 cases top 10000 in Africa | WHO | Regional Office for Africa [Internet]. [cited 2020 Sep 3]. Available from: https://www.afro.who.int/news/covid-19-cases-top-10-000-africa

10. COVID-19 in Africa: marking six months of response | WHO | Regional Office for Africa [Internet]. [cited 2020 Sep 4]. Available from: https://www.afro.who.int/covid-19-africa-marking-six-monthsresponse

11. Ilesanmi O, Afolabi A. Perception and practices during the COVID-19 pandemic in an urban community in Nigeria: a cross-sectional study. PeerJ. 2020;1-15.

12. Atas 0 , Yildrim T. Evaluation of knowledge, attitudes, and clinical education of dental students about COVID-19 pandemic. PeerJ. 2020;1-15.

13. Reuben CR, Danladi M, Saleh AD, Ejembi EP. Knowledge, Attitudes and Practices Towards COVID-19: An Epidemiological Survey in North-Central Nigeria. J Community Health [Internet]. 2020; (123456789). Available from: https://doi.org/10.1007/s10900-020-00881-1

14. Bonyan R, Al-Karasneh AF, El-Dahiyat F, Jairoun A. Identification of the awareness level by the public of Arab countries toward COVID-19: cross-sectional study following an outbreak. J Pharm Policy Pract. 2020;13(43):1-10.

\section{Supplementary Files}

This is a list of supplementary files associated with this preprint. Click to download.

- SupplementaryS1.pdf 